Pharmaceutical Research and Manufacturers of America (2010) Pharmaceutical Industry Profile 2010. Available at http://www. phrma.org/sites/default/files/159/profile_2010_final.pdf (accessed 6 March 2012).

Shuchman, M. (2007) Commercializing clinical trials - risks and benefits of the CRO boom. New England Journal of Medicine, 357 1365-1368.
Thomis, J. \& Smita, D. (2006) Outsourcing strategies. In Outsourcing Clinical Development (eds J. E. Winter \& J. Baguley), p. 14. Gower Publishing.

Tufts Center for the Study of Drug Development (2010) Tufts CSDD Outlook 2010. Available at http://csdd.tufts.edu/_documents/ www/Outlook2010.pdf (accessed 6 March 2012).

Wemos (2010) The Globalization of Clinical Trials: Testimonies from Human Subjects. Wemos.

\section{THEMATIC} PAPER

\title{
Psychiatric medicines in India: why public healthcare facilities and $a$ thriving generics industry cannot assure access and affordability
}

\author{
Anita Kotwani
}

Associate Professor, Department of Pharmacology, V.P. Chest Institute, University of Delhi, Delhi, India, email anitakotwani@ gmail.com
This commentary highlights the poor availability of essential psychiatric medicines at public sector facilities in India and illustrates why even a flourishing generics industry does not assure access to affordable psychiatric medicines for most Indian patients. The paper outlines the Indian government's pricing regulations and then enumerates recommendations for reform.

Approximately $20 \%$ of the adult population of India is affected by psychiatric disorder (Math \& Srinivasaraju, 2010). Although mental illnesses are highly prevalent in low- and middle-income countries such as India, $70-80 \%$ of these psychiatric illnesses remain untreated or do not receive evidence-based care (Patel, 2008). Additionally, patients in less developed health systems pay for medicines out of pocket, as they cannot rely on insurance or publicly financed healthcare. To address the debilitating impact of untreated mental illness, countries like India must prioritise psychiatric screening at primary health centres and improve access to psychiatric medicines.

The next section of this paper evaluates the availability of essential psychiatric medications at public facilities and private retail outlets in India. The low availability of medicines at governmentrun facilities forces patients to purchase medicines from the private sector. Although Indian generics appear relatively cheap, the low purchasing power of Indian consumers renders pharmaceutical treatment inaccessible for most psychiatric patients. The following section describes the marketing strategies of manufacturers and retailers in the thriving generics industry. Manufacturers aggressively market branded medicines to clinicians, and retailers push non-premium branded-generics directly to patients - although the two versions are chemically identical. Consequently, manufacturers and retailers have a vested interest in raising the profit margins associated with branded medicines and non-premium branded-generics respectively. The paper goes on to outline the government's pricing regulations and then enumerates recommendations for reform.

\section{Current access to essential medicines}

Notionally, Indian public facilities must provide free care and medicines. Most citizens naturally turn to the public sector for treatment. Out-ofpocket payments, however, account for up to $80 \%$ of health financing in India. Additionally, more than $70 \%$ of health spending on out-patient treatment goes towards purchasing medicines (Creese et al, 2004).

Surveys conducted using methodology developed by the World Health Organization (WHO) and Health Action International (HAI) found poor availability of a basket of 27 essential medicines for the treatment of common acute and chronic diseases in six Indian states (Kotwani et al, 2007, 2009). This basket included amitriptyline, diazepam and fluoxetine - frontline drugs for treating mental disorders. Median availability of surveyed medicines (as a proportion of the 20-60 public facilities surveyed in various states) ranged from $0 \%$ to $30 \%$. A subsequent $\mathrm{WHO} / \mathrm{HAI}$ survey in the national capital, Delhi, measured the availability of 50 essential medicines in the public sector (results available on the Health Action International website, www.haiweb.org). The mean availability of these medicines (as a proportion of the 83 public facilities surveyed) was $33 \%$, while the mean availability for amitriptyline, diazepam and fluoxetine was $6 \%, 11 \%$ and $4 \%$. These three medicines are included in the Delhi State Essential 
Medicines List (EML) as well as the National EML prepared by federal government (see www.cdsco. nic.in). Given the poor availability of key psychiatric medicines in the public sector, doctors do not prescribe them or, if they are prescribed, patients must purchase these medicines from private retailers.

The WHO/HAI survey also measured the availability and price of the originator brand, the highest-priced and the lowest-priced version of these medicines at Delhi's 40 retail pharmacies. The mean availability of the three versions for amitriptyline was $65 \%, 3 \%$ and $13 \%$ and for diazepam was $35 \%, 5 \%$ and $38 \%$. For fluoxetine, the availability of the highest-priced branded and lowest-priced version was $42 \%$ and $80 \%$ respectively.

The median unit price (price per tablet) for the branded version of amitriptyline, diazepam and fluoxetine was INR3.34 (US\$0.065), INR2.75 (US\$0.054) and INR4.85 (US\$0.095), respectively. The median unit price for the lowest-priced version of amitriptyline, diazepam and fluoxetine was INR1.86 (US\$0.036), INR2.65 (US\$0.052) and INR3.81 (US $\$ 0.075$ ), respectively. To contextualise these prices, the lowest-paid permanent government employee is paid INR247 (US\$4.84) per day. A monthly course of 90 tablets of amitriptyline would cost 1.2 days of salary for the branded version and 0.7 days of salary for the lowest-priced generic version. Nevertheless, only a small proportion of the population is publicly employed; wages are far lower in the unorganised sector, where most earn their livelihood.

\section{The generics market}

India was given exemption till January 2005 under the World Trade Organization's Agreement on Trade-Related Aspects of Intellectual Property Rights for product patents on pharmaceuticals. Pharmaceutical industries could manufacture medicines that were still under patent in other parts of the world, and this has allowed the Indian generic industry to flourish. As patent protection was not available and its implementation is still glacial, most medicines manufactured in India can be described as 'generic'. Nevertheless, medicine manufacturers want to generate brand name recognition for their product. All products have a brand (trade) name. Medicines in India are known as 'branded' and 'branded-generics'. Branded medicines are manufactured by reputable Indian manufacturers and multinational pharmaceutical companies. Medical representatives market branded medicines to prescribers, often utilising financial incentives. Branded medicines tend to be more expensive than branded-generics, but are prescribed and sold more often. Clearly, financial incentives spur doctors to prescribe branded medicines, but physicians also believe that medicines manufactured by leading companies are more likely to be of better quality.

The manufacturers of branded medicines supply their products to a carrying and forwarding (C\&F) agent. The C\&F agent is licensed to sell these medicines and distributes them to wholesalers, who in turn supply retail pharmacies.

Indian branded-generics are the equivalent of medicines referred to as generics abroad. These medicines are not truly generic, as they carry a trade name and their retail price might match that of their branded counterpart. Nevertheless, branded-generics do not have the same recognition as their influential branded equivalents. As enormous profit margins for retailers are associated with branded-generics, retailers usually try to promote them to customers. Branded-generics are mainly sold in periurban and rural areas. Branded-generic medicines are not marketed and promoted by manufacturers, which typically supply the medicine to a 'super-stockist' or wholesaler. A super-stockist is a distributor who delivers medicines to retailers, who are then encouraged to promote branded-generics. Often, doctors, unlicensed practitioners and pharmacists directly dispense branded-generics to patients.

Commonly, manufacturers make two versions of a medicine - the branded version as well as a branded-generic version. These are marketed with different trade names and are priced differently. A comparative price and quality evaluation study on five pairs of branded and brandedgeneric versions of medicines manufactured by the same company showed that both were within permitted quantitative and qualitative parameters (Singal et al, 2011). Mark-ups for retailers, however, varied considerably - those for branded products were around 25-30\%, whereas those for branded-generics varied from $201 \%$ to $1016 \%$. The five branded-generics were only $0-41 \%$ less expensive to patients than their branded versions. The branded-generic versions of alprazolam and fluoxetine cost $23 \%$ and $33 \%$ less than the branded versions.

A medicine price survey in Delhi (Health Action International, 2011) showed that manufacturers reaped the majority of the profit $(54-74 \%)$ for branded medicines and the retailer made a similar profit $(29-78 \%)$ in the case of branded-generic medicines. Thus, the greatest profit in the supply chain is accumulated by the party that markets the product.

\section{Government regulation}

A government body, the National Pharmaceutical Pricing Authority (NPPA) under the Ministry of Chemicals and Fertilizers, monitors medicine prices. The NPPA's Drug Price Control Order of 1995 (see http://nppaindia.nic.in/index1.html) identifies 74 molecules for which the government sets a maximum retail price. These 'scheduled medicines' are subject to a pricing formula, although most of them are not considered essential medicines. Chlorpromazine and trimipramine are the only psychiatric medicines among the 74 scheduled medicines.

Manufacturers set the prices for 'non-scheduled medicines' and must register those prices with the NPPA. All manufacturers print the 'Maximum 
Retail Price' (MRP) on medicine packaging and medicines are generally sold at this printed price. The NPPA does not allow the prices of nonscheduled medicines to rise more than $10 \%$ in any one year. Theoretically, market forces could check the prices of non-scheduled medicines - India's 20000 generic manufacturers should generate sufficient competition to keep prices affordable.

\section{Recommendations}

The poor availability of medicines in the public sector could be ameliorated by government pooled procurement of a sufficient regular supply of all essential medicines and increases in the drug budget. Besides these resource-intensive measures, policy-makers could undertake the following steps:

- develop and implement standard treatment guidelines for psychiatric diseases at primary and specialist facilities

- educate doctors and pharmacists to recommend cost-effective generics

- encourage consumer awareness of the affordable generic equivalents, through media campaigns

- legally permit chemists (retail pharmacists) to substitute cheaper versions.
Both federal and local governments have piloted generic drug stores that sell affordable medications (Kotwani, 2010); such stores could also stock reasonably priced psychiatric medicines.

\section{References}

Creese, A., Kotwani, A., Kutzin, J., et al (2004) Evaluating pharmaceuticals for health policy in low and middle income country settings. In Evaluating Pharmaceuticals for Health Policy and Reimbursement (eds N. Freemantle \& S. Hill), pp. 227-243. Blackwell Publishing, BMJ Books and $\mathrm{WHO}$.

Health Action International (2011) Medicines prices, availability, affordability, and price components in NCT, Delhi - using WHO/HAI methodology. Available at http://www.haiweb.org/ MedPriceDatabase/ (accessed 24 March 2012).

Kotwani, A. (2010) Will generic drug stores improve access to essential medicines for the poor in India? Journal of Public Health Policy, 31, 178-184.

Kotwani, A., Ewen, M., Dey, D., et al (2007) Medicine prices and availability at six sites in India: using the WHO-HAI methodology. Indian Journal of Medical Research, 125, 645-654.

Kotwani, A., Gurbani, N., Sharma, S., et al (2009) Insights for policymakers from a medicine price survey in Rajasthan. Indian Journal of Medical Research, 129, 451-454.

Math, S. B. \& Srinivasaraju, R. (2010) Indian psychiatric epidemiological studies: learning from the past. Indian Journal of Psychiatry, 52, S95-S103.

Patel, V. (2008) Mental health in the developing world: time for innovative thinking. Science and Development Network, 23 July. Available at http:www.scidev.net/en (accessed 4 March 2012).

Singal, G., Nanda, A. \& Kotwani, A. (2011) A comparative evaluation of price and quality of some branded versus brandedgeneric medicines of the same manufacturer in India. Indian Journal of Pharmacology, 43, 131-136.

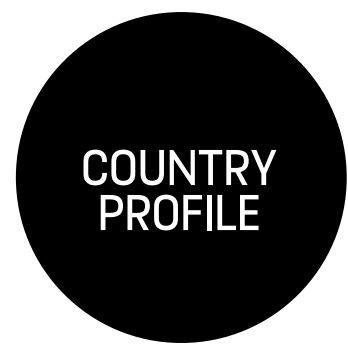

\title{
Does mental health matter? Commentary on the provision of mental health services in Mozambique
}

\author{
Kupukai Mlambo
}

Community Psychiatric Nurse, Hertfordshire Partnership NHS Foundation Trust, Stevenage CDAT, Stevenage, UK, email zimboi@hotmail.com

\begin{abstract}
Despite attempts made in recent years to address the diagnosis and treatment of mental illness in Mozambique, service provision remains deficient. The present paper focuses on the attitudes to mental illness and its diagnosis and treatment in Mozambique. This paper is based on both a thorough literature search and on the results of qualitative interviews carried out with six individuals of Mozambican origin now living in the UK.
\end{abstract}

Mozambique is a country with a population of about 21 million, characterised by low income, high rates of infectious disease (mainly malaria and HIV/AIDS), poverty, starvation and low life expectancy. Public sector services are poorly resourced. The main languages are Portuguese (the official language), Emakua, Xichangana and Elomwé. The largest religious group is Roman Catholic, although there are also many Muslims and indigenous belief systems are widespread (World Health Organization, 2005).

\section{Perception of mental health in Mozambique}

Mental illness is often interpreted in Mozambique through a traditional ancient belief system. In particular, it may be seen as retribution by the spirits of the deceased for any wrong done to them 